\title{
HISTORICIDADE DAS VIOLÊNCIAS PSICOLÓGICAS NO BRASIL E JUDICIALIZAÇÃO, A PARTIR DA LEI 11.340/06 (LEI MARIA DA PENHA)
}

\author{
THE HISTORY OF PSYCHOLOGICAL VIOLENCE IN \\ BRAZIL AND ITS JUDICIALISATION, AFTER THE \\ MARIA DA PENHA STATUTE
}

\author{
ISADORA VIER MACHADO ${ }^{1}$ \\ MIRIAM PILLAR GROSSI ${ }^{2}$
}

\begin{abstract}
RESUMO: Espera-se, aqui, a partir, prioritariamente, da construção teórica feminista nacional, resgatar como o conceito de violências psicológicas colocado na Lei Maria da Penha se construiu, na legislação e na doutrina jurídica brasileira. Nesse aspecto, buscar compreender quais os antecedentes históricos, dentro do universo jurídico, deram abertura para que se pensasse em uma espécie de violência tão distinta da física, da moral ou da sexual. Ao mesmo tempo, busca-se entrelaçar a compreensão que se constituiu ao longo do tempo (desde a Declaração Universal dos Direitos Humanos) sobre o conceito estudado e o papel que o Direito assumiu nessa conceituação. Em um quadro de docilização dos corpos, em que o Direito Público desempenha papel fundamental, pretende-se discutir como a colocação de um conceito em lei ganha projeção. Ou seja, como o conceito de violências psicológicas só passou a fazer sentido a partir do momento em que foi judicializado.

PALAVRAS-CHAVE: Violências Psicológicas; Convenção de Belém do Pará; Lei Maria da Penha; Panóptico.
\end{abstract}

\footnotetext{
Artigo recebido em 01.02.2012. Pareceres emitidos em 04.08.2012 e 08.09.2012.

Artigo aceito para publicação em 19.11.2012.

${ }^{1}$ Graduada em Direito pela Unviersidade Estadual de Maringá. Mestre em Direito pela Universidade Federal de Santa Catarina. Doutoranda pelo Programa de Pós-Graduação Interdisciplinar em Ciências Humanas da Universidade Federal de Santa Catarina (área de concentração Estudos de Gênero), em Florianópolis-SC. Bolsista CAPES. isadoravier@yahoo.com.br

${ }^{2}$ Graduada em Ciências Sociais pela Universidade Federal do Rio Grande do Sul. Mestre em Anthropologie Sociale et Culturelle - Université de Paris V (René Descartes). Doutora em Anthropologie Sociale et Culturelle - Université de Paris V (René Descartes) (1988) e Pós-doutora pelo Laboratoire d'Anthropologie Sociale do Collège de France. Professora no Programa de Pós-Graduação em Antropologia Social e no Programa de Pós-Graduação Interdisciplinar em Ciências Humanas, ambos da Universidade Federal de Santa Catarina, em Florianópolis-SC. miriamgrossi@gmail.com
} 
ABSTRACT: The aim of this article is to rescue how the concept of psychological violence placed in "Maria da Penha" Law was built in our legislation and in the Brazilian legal doctrine, using theoretical constructs from Brazilian feminists. In this way, it is important to understand the historical background, within the legal world, that allowed anyone to think about a kind of violence so different from physical, moral or sexual ones. At the same time, we seek to embrace the understanding that has been built over time (since the Universal Declaration of Human Rights) on the concept studied and the role the law took in this context. The Public Law plays a key role on bodies' regulation, which is why one of the aims of the article is also to discuss how the placement of a concept in law gains projection. Which means the concept of psychological violence only made sense from the moment it was judicialized.

KEYWORDS: Psychological Violence; Convention of Belém do Pará; "Maria da Penha Law"; Panopticum.

SUMÁRIO: Introdução; 1. Das Reivindicações à Judicialização: o itinerário da legislação brasileira; 2. Violências Psicológicas contra Mulheres no Brasil: de onde vem o conceito aposto em lei?; 3. A Judicialização das Violências Psicológicas no Brasil: possível sentido que subjaz à lei; Conclusão; Referências.

SUMMARY: Introduction; 1 . From Claims to Judicialization: the path of brazilian legislation; 2. Psychological Violence against Women in Brazil: where does the legal concept come from?; 3. Judicialization of Psychological Violence in Brazil: looking for some meanings; Conclusion; References.

\section{INTRODUÇÃO}

A "violência" tem sido tratada como fenômeno imbuído de significações próprias. Muito se fala a respeito, porém poucos esforços são empreendidos no sentido de defini-la. Delimitar esse referencial não é tão fácil quanto parece. Designa, grosso modo, uma sociabilidade em crise, caracterizadora da modernidade. ${ }^{3}$ Ou seja, é permeada por um sentido negativo. Aqui, será concebida dentro de contextos relacionais em que a pessoa violenta esvazia de sentido a pessoa violentada. ${ }^{4}$

Outro aspecto da violência que merece ser destacado é a constante ampliação de seu campo semântico. ${ }^{5}$ Quer dizer, pouco a pouco, uma extensa variedade de comportamentos é taxada de violenta, o que faz crer que a violência em si esteja aumentando. A designação de condutas em lei, taxadas como violentas, dá o tom de que a violência como problema social tem se alargado.

Recentemente, no Brasil, a Lei 11.340/06, Lei Maria da Penha, trouxe à tona a discussão sobre uma das formatações (qualificada como uma das)

\footnotetext{
${ }^{3}$ V. RIFIOTIS, Theóphilos. O Leitor-modelo no caso da Polícia Militar na Favela Naval. In: Perspectiva, v. 13, no 4, São Paulo, 1999, p. 28-41.

${ }^{4}$ Cf. FELIPE, Sônia T. Somatofobia : violência contra humanos e não-humanos; a modernidade e as vozes dissidentes contemporâneas. (parte II). Disponível em : http://www.pensataanimal.net/ index.php?option=com_content\&view=article\&id=127\&ltemid=1. Acesso em: 13 mar. 2010.

${ }^{5}$ V. RIFIOTIS, Theóphilos. Nos Campos da Violência: diferença e positividade. In: Antropologia em Primeira Mão, v. 19, p. Florianópolis, 1997, p. 10.
} 
mais comuns da violência em nossa sociedade: a doméstica e/ou intrafamiliar contra mulheres. ${ }^{6} \mathrm{O}$ enfoque privilegiado para desenvolver este artigo será o da violência conjugal. Quer dizer que o conceito adotado, a despeito de tantas discussões sobre qual seria o mais adequado, será aquele perfilhado por Miriam Pillar Grossi, em uma perspectiva distinta da violência contra a mulher, ou da violência de gênero. ${ }^{7}$ Significa, nessa linha, o conjunto de "agressões sofridas no âmbito do casamento (ou de relações afetivas com a mesma carga emocional e/ou social)" ${ }^{8}$, sejam elas físicas, sexuais, ou psicológicas. Em suma, trata-se das violências que se deslindam no âmbito da conjugalidade, sob uma perspectiva relacional. ${ }^{9}$ A opção por este referencial analítico permite pensar os contextos de violências conjugais em consonância com o parágrafo único do art. $5^{\circ}$ da Lei Maria da Penha (ou seja, independentemente da orientação sexual das mulheres envolvidas no conflito), sem restringir as mulheres à posição vitimária. De igual modo, sob a ótica relacional, confere-se maior complexidade às violências e abre-se caminho para um entendimento segundo o qual as relações de poder podem circular entre as pessoas, não havendo motivos para se subentender que a opressão em uma situação de violência psicológica será constante e intermitente sobre um único foco do casal. Em terceiro lugar, esta opção se alinha com a proposta deste artigo: discutir as situações de violências psicológicas no casal. Embora, em referência à Lei Maria da Penha, o termo violência doméstica e intrafamiliar seja eventualmente mencionado, a proposta de interpretação teórica do art. $7^{\circ}$ inc. II, da Lei 11.340/06, aqui, é dirigida às relações conjugais. Em quarto e último lugar, a escolha da terminologia violência conjugal permitiu que este texto fosse desenvolvido, sobretudo, com base na produção bibliográfica nacional, especialmente no campo das teorias feministas e de autoras brasileiras engajadas na discussão teórica das violências conjugais. ${ }^{10}$

De fato, a abordagem dessa questão não é completamente inovadora no Brasil, sequer na seara jurídica. Entretanto, é preciso reconhecer que "a doutrina ainda se ressente de uma estruturação que estabeleça a ligação

\footnotetext{
${ }^{6}$ Convém informar que esse conceito é aquele trazido pela Lei 11.340/06, Lei Maria da Penha.

${ }^{7}$ Para entender melhor a complexidade que está por trás da escolha terminológica variante entre "violência doméstica", "violência de gênero", "violência contra a mulher" ou "violência conjugal", v. ALMEIDA, Suely Souza de. Essa Violência mal-dita. In: ALMEIDA, Suely Souza de (Org.). Violência de Gênero e Políticas Públicas. Série Didáticos. Rio de Janeiro: UFRJ, 2007.

${ }^{8}$ GROSSI, Miriam Pillar. Rimando Amor e Dor: reflexões sobre a violência no vínculo afetivoconjugal. In: PEDRO, Joana Maria; GROSSI, Miriam Pillar (Orgs.). Masculino, Feminino, Plural: gênero na interdisciplinariedade. Florianópolis: Ed. Mulheres, 1998, p. 296.

${ }_{9}$ V. Também GREGORI, Maria Filomena. Cenas e Queixas: mulheres e relações violentas. Rio de Janeiro: Paz e Terra, 1993.

${ }_{10}$ Entende-se, aqui, que o uso da doutrina nacional é importante para favorecer um corpus jurídico engajado com o debate feminista. Sobretudo porque essa postura crítica é fundamental para a implementação da Lei em questão. (V. CAMPOS, Carmen Hein de. Razão e Sensibilidade: Teoria feminista do direito e Lei Maria da Penha. In: CAMPOS, Carmen Hein de (Org.). Lei Maria da Penha: comentada em uma perspectiva jurídico-feminista. Rio de Janeiro: Lumen luris, 2011).
} 
entre os aspectos antropológicos, sociais e jurídicos". ${ }^{11}$ Logo, debater as violências conjugais e as reações que suscita (em especial no plano jurídico) é uma forma de visualizar como a sociedade tem reagido à violência e como ela tem sido interpretada.

$\mathrm{Na}$ tentativa de não repetir debates que já se firmaram sobre violências conjugais, este texto procurará resgatar a historicidade de uma das várias formas de violências postas na citada Lei 11.340/06: a psicológica. A busca por antecedentes legais desta será um importante ponto de partida para questionar a demanda judicializante das violências conjugais. Entenda-se, para isso, a judicialização nos termos referidos por Rifiotis, ou seja, como

ordenamento local de práticas e valores, pressupostos em instituições como a DM [Delegacia da Mulher], que consiste fundamentalmente em interpretar a 'violência de gênero' a partir de uma leitura criminalizante e estigmatizada contida na polaridade 'vítima/agressor' ou na figura judicial do réu. ${ }^{12}$

\section{DAS REIVINDICAÇÕES À JUDICIALIZAÇÃO: O ITINERÁRIO DA LEGISLAÇÃO BRASILEIRA}

Antes de chegar ao ponto de discutir a origem do conceito legal de violências psicológicas, e assim problematizá-lo, é fundamental reaver o caminho percorrido pela legislação brasileira no que tange às violências conjugais. Tal percurso dá sentido à realidade atual, com a Lei 11.340/06, e permite vislumbrar, nos termos de Anderson Soares Gomes, "a subjetividade implícita na história". ${ }^{13}$ Ou seja, quais os caminhos, as escolhas, as omissões, os termos valorizados, os conceitos excluídos, até que se chegou a um conceito englobante, que garantiu o reconhecimento legal da violência conjugal denominada psicológica.

O Brasil, assim como demais países ocidentais que desenvolveram leis e políticas públicas voltadas para a proteção das mulheres ao longo dos anos, passou por um processo evolutivo impulsionado, principalmente, pela atividade dos grupos feministas. Esse quadro histórico do movimento feminista nacional pode ser encontrado, por exemplo, nas obras de teóricas

\footnotetext{
${ }^{11}$ PINHO, Leda de Oliveira. Princípio da Igualdade: investigação na perspectiva de gênero. Porto Alegre: Sérgio Antônio Fabris, 2005, p. 16.

12 "[...] ordenamiento local de prácticas y valores, presupuestos en instituciones como la DM, que consiste fundamentalmente en interpretar la 'violencia de género' a partir de una lectura criminalizante y estigmatizada contenida en la polaridad 'víctima/agresor' o en la figura judicial de 'reo'" (RIFIOTIS, Theóphilos. Derechos humanos y otros derechos: aporias sobre procesos de judicialización e institucionalización de movimentos sociales. In: Alejandro Isla. (Org.). En los Márgenes de la Ley. Inseguridad y Violencia en el cono sur. Buenos Aires, Barcelon, México: Paidós, 2007, p. 238).

${ }^{13}$ GOMES, Anderson Soares. Narrando Fatos: História e Historicidade em O Homem do Castelo Alto de Philip K. Dick. Disponível em: www.filologia.org.br/viiicnlf/anais/caderno07-08.html. Acesso em 16 fev. 2009.
} 
feministas brasileiras tais quais Miriam Pillar Grossi ${ }^{14}{ }_{-}^{15}$, Wânia Pasinato ${ }^{16}$, Joana Maria Pedro ${ }^{17}$, Eva Blay ${ }^{18}$, dentre outras ${ }^{19}$. O itinerário culminou com o reconhecimento legal das chamadas violências psicológicas.

No plano internacional, o desempenho dos grupos feministas permitiu a construção de uma rede normativa que foi definitiva para que o Brasil também edificasse um sistema interno de leis referentes à proteção legal das mulheres. O início do processo legislativo nacional para a proteção das mulheres se deu, conforme pontua, por exemplo, Flávia Piovesan, sob a perspectiva da proteção normativa dos direitos humanos ${ }^{20}$.

A ideia incontestável, absoluta e universal dos direitos humanos, como direitos "naturais" que dispensam pré-definição ou justificativas, de acordo com Lynn Hunt, constituiu-se ao longo do lluminismo, a partir da consolidação de ideários de individualidade e consciência moral coletiva ${ }^{21}$.

Com base nessa ideologia foi que se deram os primeiros passos em busca da igualdade de gênero, na perspectiva internacional. O que culminou com as sucessivas aprovações, em 1945 e 1948, da Carta das Nações Unidas e da Declaração Universal dos Direitos Humanos. ${ }^{22}$

Em 1975, com a realização, na Cidade do México, da I Conferência Mundial da Mulher, o sistema global de proteção aos direitos humanos deu lugar a um sistema especial preocupado em resguardar os direitos das mulheres $^{23}$, já que, à ocasião, foi aprovada pela Assembléia Geral das Nações Unidas, através da Resolução n 34/180, em 18 de dezembro de 1979,

\footnotetext{
${ }^{14}$ GROSSI, Miriam Pillar. Discours sur les Femmes Battues: représentations de la violence sur les femmes au Rio Grande do Sul. Université Paris V - René Descartes. Scinces Humaines. Paris: Sorbonne, 1988.

${ }^{15}$ GROSSI, Miriam Pillar. Identidade de Gênero e Sexualidade. Antropologia em Primeira Mão. Florianópolis: PPGAS/UFSC, 1998, p. 2.

${ }^{16}$ IZUMINO, Wânia Pasinato. Justiça e Violência contra a Mulher: o papel do sistema judiciário na solução dos conflitos de gênero. 2. ed., São Paulo: Annablume, FAPESP, 2004.

${ }^{17}$ PEDRO, Joana Maria. Traduzindo o Debate: o uso da categoria gênero na pesquisa histórica. Disponível em: http://www.scielo.br/scielo.php?script=sci_arttext\&pid=S0101-90742005000100004 \&lng=en\&nrm=iso\&tlng=pt. Acesso em: 27 dez. 2009.

${ }_{18}$ BLAY, Eva. Assassinato de Mulheres e Direitos Humanos. São Paulo: Programa de PósGraduação em Sociologia, USP: Editora 34, 2008.

${ }^{19}$ V. também GOMES, Márcia Q. de Carvalho [et Aliae.]. A Aplicação da Lei Maria da Penha em Foco. Salvador: OBSERVE, 2010.

${ }^{20}$ PIOVESAN, Flávia. A Constituição Brasileira de 1988 e os Tratados Internacionais de Proteção aos Direitos Humanos. In: BARSTED, Leila Linhares; HERMANN, Jacqueline (Coord.). As Mulheres e os Direitos Humanos: os direitos das mulheres são direitos humanos. Rio de Janeiro: CEPIA, 2001 , p. 10.

${ }^{21}$ Cf. HUNT, Lynn. O Romance e as Origens dos Direitos Humanos: interseções entre História, Psicologia e Literatura. In: Varia Historia. Belo Horizonte, vol. 2, nº 34, p. 267-289, jul. 2005.

${ }^{22}$ No plano da análise feminista nacional sobre os tratados internacionais de direitos humanos, v. BARSTED, Leila Linhares; HERRMANN, Jacqueline. Instrumentos Internacionais de Proteção aos Direitos Humanos. Rio de Janeiro: CEPIA, 1999. v. 1, p. 9.

${ }^{23}$ LIBARDONI, Alice (Coord.). Direitos Humanos das Mulheres: em outras palavras. Subsídios para capacitação legal de mulheres e organizações. Brasília: AGENDE, 2002, p. 17.
} 
a Convenção sobre a Eliminação de Todas as Formas de Discriminação contra a Mulher (CEDAW - Convention on the Elimination of All Forms of Discrimination against Women). A CEDAW foi assinada pelo Brasil em 31 de março de 1981, com algumas reservas e ratificada com a manutenção das mesmas. Ainda assim, as Nações Unidas não deixam de expressar preocupação com o número de reservas impostas pelos Estados signatários e com a postura reticente destes em retirá-las. ${ }^{24}$ Apesar disso, cabe ressaltar a importância histórica da CEDAW, cuja data de retificação pelo Brasil remonta ao dia $1^{\circ}$ de fevereiro de 1984 . Em 1994, o país retirou todas as reservas feitas à Convenção e, em 2001, finalmente assinou o Protocolo Facultativo da CEDAW. ${ }^{25}$

Em 1993, realizou-se em Viena a Conferência Mundial sobre Direitos Humanos, que resultou na Declaração sobre a Eliminação da Violência. No ano seguinte, a Assembléia Geral da Organização dos Estados Americanos adotou a Convenção Interamericana para Prevenir, Punir e Erradicar a Violência contra a Mulher - "Convenção de Belém do Pará", que reforçou a Conferência de Viena. Esta Convenção foi ratificada pelo Brasil em 27 de novembro de $1995{ }^{26}$ Sua importância reside no fato de que firmou o reconhecimento e o repúdio da OEA à violência contra as mulheres, lacuna esta que não havia sido preenchida pela CEDAW. Outrossim, em seu art. $2^{\circ}$ prenuncia que "entender-se-á que violência contra a mulher inclui violência física, sexual e psicológica" e em seu art. $4^{\circ}$, alínea $b$, inclui dentre os direitos humanos das mulheres "o direito a que se respeite sua integridade física, psíquica e moral". Perceba-se, destacadamente, que esta foi a primeira previsão legal em que a violência psicológica se inclui no conceito de violência contra a mulher.

No que tange ao contexto nacional, a história das Constituições brasileiras é também permeada pelo reconhecimento da igualdade dos cidadãos. Contudo, essa igualdade nem sempre se estendeu às relações entre homens e mulheres, restringindo-se, a princípio, a situações políticas e civis, das quais as mulheres eram peremptoriamente excluídas. Além disso, a referência era sempre à igualdade no sentido estritamente formal, sem considerar as distinções dos grupos. ${ }^{27}$ A Constituição Federal de 1988, entretanto, além de admitir a gravidade da violência doméstica e perfilhar a

\footnotetext{
${ }^{24}$ UNITED NATIONS. Division for the Advancement of Women: Convention on the elimination of all forms of discrimination against women - Reservations to CEDAW. Disponível em: http://www.un.org/womenwatch/daw/cedaw/reservations.htm. Acesso em: 19 set. 2012.

${ }^{25}$ UNITED NATIONS. Convention on the Elimination of all Forms of Discrimination Against Women: Considerations of reports submitted by States parties under article 18 of the Convention on the elimination of all forms of discrimination agains women - Brazil. Disponível em: http://daccessdds-ny.un.org/doc/UNDOC/GEN/N02/687/25/PDF/N0268725.pdf?OpenElement. Acesso em: 19 set. 2012, p. 13.

${ }^{26}$ Ibidem.

${ }^{27}$ SIQUEIRA JÚNIOR, Paulo Hamilton; OLIVEIRA, Miguel Augusto Machado de. Direitos Humanos e Cidadania. São Paulo: Revista dos Tribunais, 2007, p. 25-26.
} 
igualdade entre homens e mulheres, insere no texto constitucional um dispositivo que trata especificamente do fenômeno, um dos resultados do conhecido lobby do batom. Assim, refere o art. 226, § $8^{\circ}$ que "o Estado assegurará a assistência à família na pessoa de cada um dos que a integram, criando mecanismos para coibir a violência no âmbito de suas relações".

Muito embora tenha revertido completamente a realidade referente à violência em questão, assegurando direitos individuais por via de garantias institucionais, esse dispositivo é norma programática e, tecnicamente, de eficácia limitada, carecendo de normatividade ulterior. ${ }^{28}$

Sendo assim, no quadro da evolução legislativa que culminou com a previsão do conceito de violências psicológicas pela chamada Lei Maria da Penha, não seria possível esquecer que, em 1997, a Lei de Tortura (Lei $n^{\circ}$ 9.455/97) incluiu as violências psicológicas no conceito de tortura, ao dispor:

Art. $1^{\circ}$ Constitui crime de tortura:

[...]

II - submeter alguém, sob sua guarda, poder ou autoridade, com emprego de violência ou grave ameaça, a intenso sofrimento físico ou mental, como forma de aplicar castigo pessoal ou medida de caráter preventivo.

Pena - reclusão, de dois a oito anos.

Por certo, esta previsão não compreende especificamente os casos de violência doméstica e intrafamiliar contra mulheres e tem aplicabilidade restrita às situações enunciadas em seu próprio texto. Entretanto, confere importância à integridade psicológica e pode também ser entendida como uma abertura do ordenamento jurídico-legal à tutela deste bem.

No campo específico da proteção das mulheres em relação conjugal, Ana Lúcia Sabadel ${ }^{29}$ destaca três diplomas normativos que contribuíram para que a exigência de normas ulteriores à Constituição Federal fosse suprida. A primeira, Lei 10.455, datada de 2002, que, em artigo único, postula: "Em caso de violência doméstica, o juiz poderá determinar, como medida de cautela, seu afastamento do lar, domicílio ou local de convivência com a vítima". Em 2003, ainda, adveio a Lei 10.778, que, já em sua ementa, anuncia que "Estabelece a notificação compulsória, no território nacional, do caso de violência contra a mulher que for atendida em serviços de saúde públicos ou privados." No $\S 1^{\circ}$ de seu art. $1^{\circ}$ elucida: "Para os efeitos desta Lei, deve-se entender por violência contra a mulher qualquer ação ou conduta, baseada no gênero, que cause morte, dano ou sofrimento físico, sexual ou psicológico

\footnotetext{
${ }^{28}$ V. MENDES, Gilmar Ferreira; BRANCO, Paulo Gustavo Gonet. Curso de Direito Constitucional. 6. ed., rev. e atual. São Paulo: Saraiva, 2011, p. 87.

${ }^{29}$ SABADELL, Ana Lúcia. Perspectivas Jussociológicas da Violência Doméstica: efetiva tutela de direitos fundamentais e/ou repressão penal. Revista dos Tribunais/ Fascículo Penal. São Paulo: Revista dos Tribunais, ano 94, v. 840, p. 446.
} 
à mulher, tanto no âmbito público como no privado". Aqui, mais uma vez, o reconhecimento do dano psicológico às mulheres, como já havia sido feito por meio da "Convenção de Belém do Pará". Em 2004, com a entrada em cena da Lei $n^{\circ} 10.886 / 04$, que inseriu os $\S \S 9^{\circ}$ e 10 ao art. 129 do Código Penal, a violência doméstica foi penalmente tipificada.

Várias críticas foram apontadas, especialmente ao $\S 9^{\circ}$ da Lei, que define o delito de violência doméstica como a lesão corporal praticada "contra ascendente, descendente, irmão, cônjuge ou companheiro, ou com quem conviva ou tenha convivido, ou, ainda, prevalecendo-se o agente, das relações domésticas, de coabitação ou hospitalidade". Como infere Ana Lúcia Sabadell:

A formulação dada ao $\S 9^{\circ}$ do art. 129 do $\mathrm{CP}$ indica que houve um retrocesso em termos de política criminal: o legislador não quer problematizar as relações patriarcais e subtrai do conceito de violência doméstica a referência do gênero e ao tipo patriarcal de relação. Encontramos aqui uma norma que, referindo-se formalmente à violência doméstica, objetiva, na realidade, absolver o patriarcalismo. ${ }^{30}$

Como continuidade da conjuntura debatida, houve uma mudança fundamental no quadro legislativo brasileiro, a partir de 7 de agosto de 2006, com a promulgação da Lei 11.340, nomeada pelo Presidente da República de "Lei Maria da Penha". Esse diploma, consoante seu preâmbulo, cria mecanismos para coibir a violência doméstica e familiar contra a mulher, nos termos do $\S 8^{\circ}$ do art. 226 da Constituição Federal, da Convenção sobre a Eliminação de Todas as Formas de Discriminação contra as Mulheres e da Convenção Interamericana para Prevenir, Punir e Erradicar a Violência contra a Mulher, além de outras providências. Por sua vez, em seu art. $7^{\circ}$, define que as violências podem ter como manifestações as formas física, psicológica, sexual, patrimonial e moral.

A Lei resultou dos esforços de Maria da Penha, brasileira vítima de seguidos atos de violências conjugais. Em setembro de 1997, ela, com o auxílio da entidade não-governamental Centro pela Justiça e o Direito Internacional (CEJIL) e do Comitê Latino-Americano e do Caribe para a Defesa dos Direitos da Mulher (CLADEM), elaborou uma petição sobre o caso, para ser encaminhada à Comissão Interamericana de Direitos Humanos, nos termos do art. 44 do Pacto de São José da Costa Rica.

Diante disso, em 20 de agosto de 1998, a Comissão recebeu a denúncia (caso 12.051) e, por quatro vezes, solicitou informações ao governo brasileiro, ao que nunca obteve resposta. Face à omissão das autoridades nacionais e ante a violação de inúmeros direitos previstos na Convenção Americana de Direitos Humanos, a Comissão Interamericana aprovou e publicou, em 16 de abril de 2001, o Relatório 54. Este informe continha, dentre suas

${ }^{30}$ SABADELL, Ana Lúcia. Perspectivas Jussociológicas da Violência Doméstica, p. 448. 
recomendações, aquela de que o Estado brasileiro deveria prosseguir e intensificar o processo de reforma a fim de evitar tolerância estatal e tratamento discriminatório das mulheres, mormente em casos de violência doméstica. ${ }^{31}$

Todas as conclusões apontadas pela Comissão convergiam para a óbvia constatação de que a impunidade do infrator in casu decorria, tãosomente, de ineficácia judicial. Em março de 2002, o Brasil finalmente apresentou considerações a respeito do caso, em uma reunião junto à OEA, comprometendo-se a cumprir a recomendação.

Em 2004, entrou em vigor a Lei 10.886/04, impulsionada, inclusive, pela suposta condenação internacional ${ }^{32}$ que o Brasil havia sofrido. O próprio Projeto de Lei $n^{0}$ 03/2003 faz referência a esse fato e utiliza-o como uma de suas justificativas. ${ }^{33}$ Entretanto, também sublinhou-se a confusão gerada pela Lei em comento, já que não tutelou significativamente as mulheres.

Assim, paralelamente a todas essas mudanças, a partir de 2003 já vinha sendo elaborado o novo projeto de lei, sob a coordenação da então Secretaria Especial de Políticas para as Mulheres, visando cumprir com mais afinco as recomendações apontadas. Em novembro de 2004, o Projeto foi encaminhado ao Congresso Nacional. Informa Maria Berenice Dias que a "Deputada Jandira Feghali, relatora do Projeto de Lei 4.559/2004, realizou audiências públicas em vários Estados e apresentou substitutivo". ${ }^{34}$ Em 7 de agosto de 2006, o Presidente da República sancionou a Lei 11.340 que está em vigor desde o dia 22 de setembro de 2006.

\section{VIOLÊNCIAS PSICOLÓGICAS CONTRA MULHERES NO BRASIL: DE ONDE VEM O CONCEITO APOSTO EM LEI?}

Para dar sentido ao presente conceito de violências psicológicas, foi necessário percorrer o caminho inverso, rumo ao passado dessa construção legal. De acordo com Anderson Soares Gomes, "é a historcidade que dá caráter factual à vivência". Ainda, em suas palavras "esse distanciamento do presente é o que possibilita, então, o entendimento da época em que se vive como momento histórico, o que cria a historicidade em ações, objetos, personagens e transforma acontecimentos cotidianos em fatos". ${ }^{35}$

\footnotetext{
${ }^{31}$ V. ESTIGARA, Adriana. O Dever de Adotar Políticas Públicas em Decorrência da Atuação do Sistema Interamericano de Direitos Humanos: uma análise a partir dos casos "Maria da Penha" e "Damião Ximenes". In: PIOVESAN, Flávia; IKAWA, Daniela (Coord.). Direitos Humanos Fundamentos, Proteção e Implementação: perspectivas e desafios contemporâneos, p. 464.

${ }^{32}$ Fala-se "suposta" porque, na realidade, não houve condenação formal e sim recomendações a serem atendidas.

${ }^{33}$ BRASIL. Projeto de Lei nº3/2003. Câmara dos Deputados. Disponível em: http://uww2.camara.gov.br/ proposicoes/loadFrame.html?link=http://www.camara.gov.br/internet/sileg/prop_lista.asp?fMode=1\&btn Pesquisar=OK\&Ano=2003\&Numero=3\&sigla=PL. Acesso em: 11 nov. 2008.

${ }^{34}$ DIAS, Maria Berenice. A Lei Maria da Penha na Justiça: a efetividade da Lei 11.340/06 de combate à violência doméstica e familiar contra a mulher. São Paulo: Revista dos Tribunais, 2007, p. 14.

${ }^{35}$ GOMES, Anderson Soares. Narrando Fatos: História e Historicidade em O Homem do Castelo Alto de Philip K. Dick. Disponível em: www.filologia.org.br/viiicnlf/anais/caderno07-08.html. Acesso em 16 fev. 2009, p. 5-6.
} 
De tal forma, prossegue-se no resgate daquilo que impulsionou o reconhecimento legal das chamadas violências psicológicas. Conforme referido no item precedente, com a Convenção Interamericana para Prevenir, Punir e Erradicar a Violência contra a Mulher desvelou-se, pela primeira vez, um conceito legal de violência psicológica. Essa iniciativa foi reproduzida pela Lei 11.340/06, Lei Maria da Penha.

A importância em debater o tema se lastra também nos números apontados pelas estatísticas. No Brasil, por exemplo, de 2.502 mulheres entrevistadas pela Fundação Perseu Abramo, no ano de 2001, cerca de uma a cada cinco declararam ter sofrido violência por homens. Destas, 33\% relataram casos de violência física; $27 \%$ citaram violências psíquicas e $11 \%$, assédio sexual. ${ }^{36}$ Nesse sentido, reconheceu-se que a violência física é apenas uma dentre outras possibilidades a se vivenciar na relação conjugal.

É claro que, antes de se firmar como um dispositivo de lei, já havia pesquisas acadêmicas sobre o tema das violências psicológicas no casal, de modo geral, desenvolvidas nos campos da Psicologia e do Serviço Social. No Brasil, a temática é abordada, mais recentemente, via de regra, sob a denominação de assédio moral. No campo teórico, a prática do assédio moral é definida pelos seguintes elementos caracterizadores:

a) permanência no tempo: a exigência de continuidade, constância, é insistentemente ressaltada, levando em conta que a violência psicológica não se firma caso as agressões veladas não ocorram de maneira reiterada; b) sutileza: o agressor desenvolve mecanismos de comunicação, para que os outros não percebam a violência dirigida à vítima. Utiliza-se do discurso indireto, tortuoso, que pode conduzir à interpretação vaga daquilo que diz, confundindo, propositadamente, a vítima; ${ }^{37}$ c) bilateralidade: a presença de um agressor e de uma vítima assediada sustentada por uma circunstância de dominação ou superioridade hierárquica. ${ }^{38}$

\footnotetext{
${ }^{36}$ Para maiores detalhes sobre a pesquisa, v. ROVINSKI, Sonia Liane Reichert. Dano Psíquico em Mulheres Vítimas de Violência. Rio de Janeiro: Lumen Juris, 2004, p. 14.

37 "A agressão não se dá abertamente, pois isso poderia permitir um revide; ela é praticada de maneira subjacente, na linha da comunicação não-verbal: suspiros seguidos, erguer de ombros, olhares de desprezo, ou silêncios, subentendidos, alusões desestabilizantes ou malévolas, observações desabonadoras [...]". (HIRIGOYEN, Marie-France. Assédio Moral: a violência perversa no cotidiano. Rio de Janeiro: Bertrand Brasil, 2002, p. 77).

38 "No assédio moral, o assediador e assediado encontram-se em uma situação de desigualdade, sendo que o assediador, de algum modo específico, exerce uma postura de dominação ou detém superioridade hierárquica sobre a pessoa que está sendo assediada. Assim, a primeira característica do assédio moral seria a posição de superioridade ou dominação (econômica, intelectual, poder familiar) em relação ao assediado (empregados, esposa, professores, filhos em relação aos pais). (SANTOS, Luciany Michelli Pereira dos. Assédio Moral nas Relações Privadas: uma proposta de sistematização sob a perspectiva dos direitos da personalidade e do bem jurídico integridade psíquica, 250 fls. Dissertação [Mestrado em Direito Civil]. Universidade Estadual de Maringá, Maringá, 2006, p. 124).
} 
Considera-se que esse tipo de violência se dá em uma escala gradual. As agressões físicas, por sua vez, são consequências do procedimento insidioso que já se havia instaurado através do terrorismo psicológico. Os procedimentos do assédio moral também são específicos: ${ }^{39}$

a) Recusa de comunicação direta: as mensagens são repassadas por bilhetes, ou são curtas, às perguntas não se dão respostas etc.; b) Deformação da linguagem: as mensagens são subliminares, vastas, imprecisas; c) Mentiras: usadas para anular a responsabilidade de quem as veicula; d) Manejo do sarcasmo, da ironia e do menosprezo: fazer uso do cinismo a fim de criar um ambiente extremamente desagradável; e) Desestabilização da vítima por mensagens contraditórias: deixar a outra pessoa em constante dúvida para que ela mesma questione seu próprio conhecimento e suas atitudes; f) Desqualificação: rebaixar, criticar.

O que na França surgiu com a definição de assédio moral, a americana Mary Susan Miller já havia identificado nos Estados Unidos, com a denominação de abuso não-físico: "o abuso não-físico, de qualquer tipo, é a destruição acumulada do bem-estar emocional, psicológico, social e econômico de uma mulher". ${ }^{40}$ Trata-se do mesmo processo, em que a manipulação constante é tipicamente alternada com momentos de concórdia, para dar a falsa sensação de que, com o tempo, tudo vai melhorar. Também neste caso a prática é sutil e repetitiva e o abuso psicológico é definido como o estado de confusão mental que se procura instalar.

No Québec (Canadá), em pesquisa sobre violências psicológicas, realizada com casais de idosos, a assistente social Lyse Montminy ${ }^{41}$ arrolou como práticas configuradoras destas violências as seguintes: controle; ato de denegrir a imagem do outro; depredação de seus bens; intimidação; abdicação da responsabilidade; ameaças; manipulação; culpabilização; indiferença; assédio; negação da realidade; comportar-se de modo insociável, reprimindo sua raiva, com mal-humor; infantilização. A autora também identificou que a violência psicológica se dá não somente por aquilo que os maridos/companheiros efetivamente fazem às mulheres (como as ameaças, por exemplo), mas também por aqui que eles não fazem (como a indiferença).

Sobre as consequências produzidas pelo fenômeno, Maria Berenice Dias destaca que "a ferida sara, os ossos quebrados se recuperam, o sangue seca, mas a perda da auto-estima, o sentimento de menos valia, a depressão, essas são feridas que não cicatrizam". ${ }^{42}$ Nessa mesma linha, os sintomas psicológicos apontados pela psicóloga Sonia Rovinski são: choque, negação,

\footnotetext{
${ }^{39}$ Cf. HIRIGOYEN, Marie-France. A Violência no Casal: da coação psicológica à agressão física. Rio de Janeiro: Bertrand Brasil, 2006, p. 98-99.

${ }^{40}$ MILLER, Mary Susan. Feridas Invisíveis: abuso não-físico contra mulheres. São Paulo: Summus, 1999, p. 21.

${ }^{41}$ MONTMINY, Lyse. Older women's experiences of psychological violence in their marital relationships. Disponível em: http://www.haworthpress.com/web/JGSW, 2005.

${ }^{42}$ DIAS, Maria Berenice. A Lei Maria da Penha na Justiça, p. 20.
} 
recolhimento, confusão, entorpecimento, medo, depressão, desesperança, baixa auto-estima e negação. ${ }^{43}$ Já Antonio García-Pablos de Molina e Luiz Flávio Gomes, ao remeter à obra de Enrique Esbec Rodriguez e Gregório Gomes Jarabo, ensinam que a vitimização psíquica é um problema grave e que pode gerar as seguintes consequências:

[...] sentimentos de humilhação, ira, vergonha e impotência; preocupação constante pelo trauma; auto-culpabilização, com tendência a reviver e perceber o acontecimento como responsável principal pelo mesmo; perda progressiva de autoconfiança pelos sentimentos de impotência por ela experimentados; alteração do sistema de valores, em particular, quebra de sua confiança nos demais e na existência de uma ordem justa; falta de interesse e motivação para atividades e afeições prévias; incremento de sua vulnerabilidade com temor a viver em um mundo perigoso e perda de controle de sua própria vida; diminuição da auto-estima; ansiedade, depressão, agressividade; alterações do ritmo e conteúdo do sono, disfunções sexuais; dependência e isolamento; mudanças drásticas no estilo de vida, medo de freqüentar os lugares de costume etc. ${ }^{44}$

Mas como as violências psicológicas foram parar em lei? Ao se retomar a discussão sobre o itinerário legal que conduziu ao reconhecimento das violências psicológicas como forma de violência conjugal, percebe-se que a violência doméstica foi inserida no Código Penal brasileiro como crime (com esse exato nomen juris), por meio da Lei 10.886/04. O diploma legal acrescentou dois parágrafos ao art. 129 (lesão corporal - "ofender a integridade corporal ou a saúde de outrem") do referido Código ( $\S \S 9^{\circ}$ e 10), instituindo o que se chama de qualificadora ao delito base do caput (que é a lesão corporal simples), já que a pena deste (para a lesão simples) é de detenção de três meses a um ano e a do $\S 9^{\circ}$ (violência doméstica) é de três meses a três anos. ${ }^{45}$

Ressalve-se que o § $9^{\circ}$ fala: "se a lesão for praticada contra ascendente, descendente, irmão, cônjuge ou companheiro, ou com quem conviva ou tenha convivido, ou, ainda, prevalecendo-se o agente das relações domésticas, de coabitação ou de hospitalidade". Ao mencionar apenas a palavra lesão, remete naturalmente ao caput do art. 129, do CP, significando, portanto, "ofender a integridade corporal ou a saúde de outrem". Sendo assim, tecnicamente, considera-se violência doméstica a ofensa à integridade corporal ou à saúde de ascendente, descendente, irmão, cônjuge ou companheiro, ou com quem o sujeito ativo conviva ou tenha convivido, ou, ainda, prevalecendo-se este mesmo agente das relações domésticas, de coabitação ou de hospitalidade.

\footnotetext{
${ }^{43}$ ROVINSKI, Sonia Liane Reichert. Dano Psíquico em Mulheres Vítimas de Violência, p. 78.

${ }^{44}$ RODRIGUEZ, Enrique Esbec; JARABO, Gregório Gomes. Psicología Forense y Tratamiento Jurídico Legal de la discap. Apud: MOLINA, Antonio García-Pablos de Molina; GOMES, Luiz Flávio. Criminologia. 4. ed., rev., atual e ampl. São Paulo: Revista dos Tribunais, 2002, p. 86-87.

${ }^{45}$ Isso, após a Lei 11.340/06. Antes, o que se tinha era uma pena de 06 meses a 01 ano.
} 
A Lei 11.340/06 surgiu em meio a um contexto em que restou consignada a insuficiência da Lei $10.886 / 04$, diante das demandas crescentes de violência. Sua elaboração foi acompanhada de um movimento internacional intenso, reivindicatório de mudanças na América Latina como um todo. Nesse percurso, fica claro que o conceito de violências psicológicas adotado pela lei brasileira, em seu art. $7^{\circ}$, inc. II, é muito próximo ao conceito pontuado em outras leis latino-americanas. Deu-se conta que, na realidade, os distintos conceitos remetem a um documento internacional de caráter informativo, intitulado "Modelo de Leyes y Políticas sobre violencia intrafamiliar contra las mujeres". ${ }^{46}$

É nítido que diversas mudanças foram produzidas pela nova lei brasileira, mas, na essência, não se criaram crimes novos. Assim, na verdade, o Modelo de Leyes engloba disposições do art. $2^{\circ}$ da "Convenção de Belém do Pará", admite que:

Art. $7^{\circ}$ São formas de violência doméstica e familiar contra a mulher, entre outras:

[...]

II - a violência psicológica, entendida como qualquer conduta que lhe cause dano emocional e diminuição da auto-estima ou que lhe prejudique e perturbe o pleno desenvolvimento ou que vise degradar ou controlar suas ações, comportamentos, crenças e decisões, mediante ameaça, constrangimento, humilhação, manipulação, isolamento, vigilância constante, perseguição contumaz, insulto, chantagem, ridicularização, exploração e limitação do direito de ir e vir ou qualquer outro meio que lhe cause prejuízo à saúde psicológica e à autodeterminação;

$[\ldots]$

A despeito do reconhecimento que implica colocar tal conceito em lei, o simples fato de se ter admitido a modalidade de violência em comento não significa a criação de um crime de violência psicológica. Saliente-se que o art. $7^{\circ}$ constitui apenas um parâmetro de interpretação de quando a lei pode ser aplicada. Ou seja, cada espécie de violência relevada no dispositivo deve se enquadrar em algum injusto penal já existente, tendo a nova lei importância meramente conceitual e restrita ao espaço jurídico de seus próprios artigos. Abstrai-se, pois, uma aceitação passiva dessa "nova" forma de designação violenta. Por que motivo, então, definir esse conceito em lei?

Pode-se dizer que a Lei Maria da Penha, vigente desde 2006, traz três dimensões fundantes: uma dimensão normativa, uma dimensão protetiva e uma dimensão pedagógica. Em um plano normativo, a Lei trouxe alterações fundamentais, tanto no campo penal, quanto processual penal, como o

\footnotetext{
${ }^{46}$ Disponível em: http://new.paho.org/hq/index.php?option=com_content\&task=view\&id=91\&ltemid=220. Acesso em: 10 ago. 2011.
} 
aumento de pena nos casos de lesão corporal pelo art. 129 , § $9^{\circ}$ do Código Penal; retirada da competência dos Juizados Especiais; proposta de criação facultativa dos Juizados de Violência Doméstica e Familiar; aumento das hipóteses de prisão preventiva pelo CPP brasileiro, etc. Foi sob este plano que se salientou a chamada judicialização das violências domésticas e familiares contra mulheres.

Por outro lado, em um plano protetivo, a mesma lei dispõe de uma série de mecanismos para prevenção, intervenção e tratamento dos casos em que as mulheres se encontrem em situação de violências. Assim falamos das já conhecidas medidas protetivas, da proposta para que se criem serviços de tratamento aos/às autores/as de violências; da proposição para que o trato das questões relativas às violências contra mulheres se dê no âmbito de uma rede de atendimento devidamente articulada, etc.

O que interessa, particularmente, é a terceira dimensão. A dimensão pedagógica. Por meio dela é que se lançou mão de uma compreensão de 'violências domésticas e familiares contra mulheres', com base no gênero, como a própria lei refere. Essa dimensão é destacada, primordialmente, nos artigos $5^{\circ}$ e $7^{\circ}$ da Lei, que definem a concepção de violências adotada nesse documento.

Diante da dimensão pedagógica com a qual estamos lidando, já se sabe que, para que, tecnicamente, uma conduta seja considerada crime, deve ser dotada de uma estrutura jurídica específica, que inclui a previsão de uma ação ou omissão, contrária ao Direito e pela qual o agente tenha condições mínimas de responder penalmente.

Contudo, não parece haver nenhum crime que alcance toda a abrangência conceitual do que a Lei Maria da Penha concebe como violências psicológicas. Embora haja algumas condutas que se aproximam de algumas estratégias de consolidação dessas violências - como os crimes de ameaça ("Ameaçar alguém, por palavra, escrito ou gesto, ou qualquer outro meio simbólico, de causar-lhe mal injusto e grave") e constrangimento ilegal ("Constranger alguém, mediante violência ou grave ameaça, ou depois de the haver reduzido, por qualquer outro meio, a capacidade de resistência, a não fazer o que a lei permite, ou a fazer o que ela não manda"); ou a contravenção penal (infração de menor importância ofensiva) de perturbação da tranqüilidade "(Molestar alguém ou perturbar-lhe a tranqüilidade, por acinte ou por motivo reprovável"). Lembrando que a injúria é definida como violência moral pela lei, e não violência psicológica.

Ou seja, dado todo o itinerário aqui já descrito, percebe-se que a Lei 11.340/06, enfim, produziu inegável a valorização da integridade psicológica pelo legislador. $\mathrm{O}$ reconhecimento das violências psicológicas ${ }^{47}$ veio a exultar

\footnotetext{
${ }^{47}$ A diferenciação entre violência psicológica e psíquica (ou integridade psicológica e psíquica), para o Direito, parece inócua. Para a psicologia, no entanto, denotam situações diversas. A violência psíquica seria causadora de uma patologia médica; enquanto que a psicológica
} 
este bem jurídico, qual seja, a integridade psicológica, firmando sua real importância para as mulheres em situação de violências. Mas isso só foi possível em razão de toda trajetória que se consolidou no passado, com outras normativas nacionais e internacionais.

Mesmo assim, a judicialização das violências psicológicas instituiu uma aura de descrédito em meio a outros doutrinadores. É exatamente nesse sentido que Luis Paulo Sirvinskas externa sua perplexidade:

Merece, no entanto, especial destaque a violência psicológica. Pode-se notar que o rol é extenso e qualquer atitude, por menor que seja, poderá caracterizar essa modalidade de violência, especialmente quando o marido ridicularizar a mulher por brincadeira, por exemplo. Parece-nos um exagero desnecessário. Como amoldar estas condutas aos tipos penais existentes? ${ }^{48}$

A combater a tese daqueles que dizem que a prática de qualquer infortúnio já configuraria violência psicológica, a penalista Érika Mendes de Carvalho se opõe:

As meras desavenças conjugais ou familiares e as discussões que provocam apenas perturbações emocionais incapazes de comprometer ou afetar a integridade psíquica da vítima não se encontram incluídas, portanto, no âmbito da violência doméstica, pois é preciso que se constate uma certa magnitude na violência psíquica e que esta se concretize em efetivo menoscabo da saúde psíquica. ${ }^{49}$

Parece que outra razão que impede o reconhecimento de uma modalidade de violência psicológica é a dificuldade probatória. Não raro, inclusive o juiz se mostrará cético diante da prática de um suposto ato que não tem como ser provado. Desse modo, a judicialização de violências psicológicas pode trazer complicações.

\section{A JUDICIALIZAÇÃO DAS VIOLÊNCIAS PSICOLÓGICAS NO BRASIL: POSSÍVEL SENTIDO QUE SUBJAZ À LEI}

Há um sentido subjacente à existência de um conceito de violência em lei. Para além do fato de ser a lei uma fonte primária do Direito, todas as

não poderia gerar qualquer tipo de patologia somática. (Cf. BENÍTEZ ORTÚZAR, Ignácio F. La Violencia Psíquica a la luz de la Reforma del Código Penal en materia de Violencia Doméstica. Disponível em: http://premium.vlex.com/doctrina/Estudios-penales-violencia-domestica/Violenciapsiquica-luz-reforma-codigo-penal-materia-violencia-domestica/2100-298577,01.html. Acesso em: 11 nov. 2008).

${ }^{48}$ SIRVINSKAS, Luis Paulo. Aspectos polêmicos sobre a Lei $n^{0}$ 11.340, de 7 de agosto de 2006, que cria mecanismos para coibir a violência doméstica e familiar contra a mulher, Revista Jurídica, ano 55, n 351, Porto Alegre: Nota Dez/Fonte do Direito, jan. 2007, p. 112.

49 CARVALHO, Érika Mendes de. O Tratamento Penal da Violência Doméstica no Brasil: uma abordagem crítica. Revista da Associação Brasileira de Professores de Ciências Penais. São Paulo, ano 3, p. 207-233, jan./jul. 2006, p. 218. 
discussões que se produziram no campo jurídico a respeito das violências psicológicas dão indícios da projeção que a definição ganhou, ao ser destacada pela Lei Maria da Penha. Por certo, condutas previamente existentes, como ameaça, ou constrangimento ilegal, já eram objeto de teorização no Direito. Assim como as violências psicológicas eram objeto de teorização em outros campos. A questão que se impõe é pensar sobre o significado de se colocar um conceito de violências psicológicas em lei. Mais ainda, na primeira lei que resultou da luta feminista nacional, destinada especificamente à tutela de mulheres em situação de violências. É evidente que o art. $7^{\circ}$, inc. II, da Lei 11.340/06 tem muito a dizer.

De acordo com Lynn Hunt ${ }^{50}$, ao citar Foucault, afirmar novos direitos é também um pretexto para que se dê abertura a um processo de imposição de disciplina. O modelo disciplinar vigente, de acordo com Foucault, é o da "disciplina-mecanismo", representado metafórica e arquitetonicamente pelo Panóptico de Bentham. ${ }^{51}$ Nas palavras do referido autor: "O panoptismo é o princípio geral de uma nova 'anatomia política' cujo objeto e fim não são a relação de soberania, mas as relações de disciplina". ${ }^{52}$ Quer dizer com isso que o poder é constitutivo da sociedade. Não se exerce sobre ela, mas sim a integra, em um constante jogo de violência e consentimento, de modo que não há qualquer possibilidade de se viver sem esse tipo de relação, o que constituiria a mais pura abstração. ${ }^{53}$ Dessa forma, o poder integra o próprio mecanismo de subjetivação dos sujeitos.

A partir dessa virada histórica, a produção de saber articula-se com uma lógica de poder marcado pela atuação do Estado, ao mesmo tempo totalizadora e individualizante. A marca individualizante foi herdada do que Foucault chama de poder pastoral, o poder característico do cristianismo, em que o pastor guiava suas ovelhas e constituía a salvação de cada uma delas. Hoje em dia, esse poder, supostamente garantidor da salvação dos indivíduos, encontra eco em praticamente todas as instituições sociais, tendo sido apropriado pelo Estado. ${ }^{54}$

\footnotetext{
${ }^{50}$ HUNT, Lynn. O Romance e as Origens dos Direitos Humanos, p. 278.

51 "O princípio é conhecido: na periferia uma construção em anel; no centro, uma torre; esta é vazada de largas janelas que se abrem sobre a face interna do anel; a construção periférica é dividida em celas, cada uma atravessando toda a espessura da construção; elas têm duas janelas, uma para o interior, correspondendo às janelas da torre; outra, que dá para o exterior, permite que a luz atravesse a cela de lado a lado. Basta então colocar um vigia na torre central, e em cada cela trancar um louco, um doente, um condenado, um operário ou um escolar. Pelo efeito da contraluz, pode-se perceber da torre, recortando-se exatamente sobre a claridade, as pequenas silhuetas cativas nas celas da periferia". (FOUCAULT, Michel. Vigiar e Punir: história da violência nas prisões. 37. ed., Rio de Janeiro: Vozes, 2009, p. 190)

${ }^{52}$ Ibidem, p. 197.

${ }^{53}$ V. FOUCAULT, Michel. O Sujeito e o Poder. In: RABINOW, Paul; DREYFUS, Hubert. Michel Foucault: uma trajetória filosófica - para além do estruturalismo e da hermenêutica. Rio de Janeiro: Forense Universitária, 1995.

${ }^{54}$ Ibidem.
} 
Nesse contexto, Foucault afirma que os processos jurídicos-políticos têm papel fundamental, especificamente com a

[...] formação de um quadro jurídico codificado, formalmente igualitário e difundido em sistemas de micropoder, submetendo os sujeitos ao mesmo tempo em que são hierarquizados, desqualificados e invalidados por uma estrutura de poder assimétrico em uma espécie de "contradireito" 55.

Para Hannah Arendt, em uma passagem de seu livro Responsabilidade e Julgamento ${ }^{56}$, a busca forçada por se promover a igualdade por meio da atuação estatal só pode ter um resultado: o ressentimento cada vez maior entre aqueles que são evidentemente diferentes. A sociedade é por ela retratada como um misto constante entre público e privado, e o que nos leva da última à primeira é a necessidade de ganhar a vida. Nesse quadro, a discriminação é apresentada por Arendt como um direito social, indispensável enquanto mantido em um nível que não ultrapasse para a esfera política e pessoal, quando, então, se torna destrutiva. O que interessa, particularmente, aqui, é a terceira esfera da vida destacada por Arendt: a da privacidade. Nesta, as pessoas escolhem, objetivamente, com quem querem conviver, sem dar conta de raça, gênero, cor, etc., ou do tipo de relação que se estabelece (seja ela violenta, ou não). Só há intervenção nessa esfera quando as relações passam a infringir preceitos legais, que asseguram direitos às pessoas.

Ou seja, no âmbito da privacidade, existe um limite claro de intervenção. Limite que só se rompe quando há infringência legal. É certo, conforme Hannah Arendt ainda, que essa lei jamais pode resultar de um simples capricho social. Porém, não há como ignorar o fato de que o espaço da privacidade, a partir de reivindicações constantes dos grupos feministas, associações de mulheres em lutas coletivas pelo fim das violências, deu lugar à atuação em sociedade, do Estado.

Há que se compreender, então, que a despeito do controle e da vigilância estatal que uma lei produz, por trás dela existe uma historicidade que the atribui sentido. O percurso legislativo, certamente, tinha como fundamento implícito a atribuição ao Estado da tutela de situações de violências. O que indica, contudo, que, em determinado momento, essa tutela se constituiu como importante estratégia política de controle das mais diversas formas de violência conjugal. Com o tempo, conforme se esclareceu no item precedente,

\footnotetext{
${ }^{55}$ FOUCAULT, Michel. Vigiar e Punir, p. 210.

${ }^{56}$ A referência, aqui, é ao caso de Little Rock, no trecho "Reflexões sobre Little Rock", em que a autora discute uma decisão judicial que autorizou uma garota norte-americana, negra e sulista, a frequentar uma escola de brancos no norte do país. Houve uma integração forçada de brancos e negros nas escolas públicas norte-americanas. Porém, diante de uma foto que registrou o momento de saída dessa garota da escola, vê-se em seu rosto o descontentamento pelo fato de não ser desejada naquele ambiente. (ARENDT, Hannah. Responsabilidade e Julgamento. São Paulo: Companhia das Letras, 2004, p. 260-281).
} 
o mesmo controle se estendeu a outras formas de violências, já reconhecidas por doutrinas diversas (como a Psicologia, ou o Serviço Social), mas até então, negadas pelo universo jurídico. Como afirma Reinhart Koselleck, "presente e passado estariam, assim, circundados por um horizonte histórico comum". ${ }^{57}$

Não há, pura e simplesmente, como desconstituir o elo entre passado e presente, ignorando a presença do conceito de violências psicológicas em lei. Daí surgir, entre juristas, em contextos dos mais diversos, dissenso sobre a existência ou não de uma violência caracteristicamente psicológica. Após a judicialização dessa categoria, muitas pessoas foram receptivas ao conceito, enquanto outras se mostraram extremamente resistentes.

De um jeito ou de outro, o reconhecimento legal das violências psicológicas, fruto de um quadro histórico que foi aqui exposto, tem algo a dizer, por si só. Quer dizer que a luta pela erradicação das violências contra mulheres não deve esperar que as feridas marquem o corpo, porque às vezes elas são invisíveis. Quer dizer que precisamos pensar em como utilizar a dimensão protetiva da Lei Maria da Penha em toda a sua abrangência, evitando que se privilegiem as estratégias judicializantes. E quer dizer, acima de tudo, que é passada a hora de reconhecer que a palavra das mulheres tem valor.

\section{CONCLUSÃO}

A categoria violências psicológicas resultou de um trajeto histórico que se fortaleceu com as lutas feministas, e reverberou nas diversas normativas internacionais e nacionais aqui descritas, culminando, no Brasil, com a promulgação da Lei 11.340/06 (Lei Maria da Penha). Nesse diploma legal, pela primeira vez, aparece uma definição daquilo que se entende, no campo do Direito, por essas violências. O conceito trazido enfim aproxima a compreensão jurídica daquela havida em outros campos, como Psicologia ou Serviço Social.

É certo que, antes do aparecimento da citada Lei, outros crimes abrangiam práticas de violências psicológicas, tais quais ameaça, ou constrangimento ilegal, mas é necessário buscar um sentido que justifique o destaque em lei da categoria em questão.

Os reflexos gerados foram variados. Houve severa crítica, por se acreditar que tais violências não merecem o mesmo destaque ou o mesmo trato que, por exemplo, violências físicas ou sexuais. Além do que, seu reconhecimento suscita uma série de dificuldades, como os obstáculos probatórios.

Pode parecer evidente que se trata de mais uma forma de controle estatal, dado o fato que, quanto mais direitos são atribuídos sob tutela do Estado, maior é o grau de vigilância que se coloca sobre as pessoas, diminuindo sua esfera de autonomia e liberdade privada.

57 KOSELLECK, Reinhart. O Futuro Passado dos Tempos Modernos. In: Futuro Passado. Contribuição à semântica dos tempos históricos. Rio de Janeiro: Editora PUC Rio, 2006, p. 22. 
Entretanto, o que pode parecer uma ingerência desmedida no âmbito conjugal, pode também ser visto de outra forma. E é justamente a historicidade do conceito de violências psicológicas que autoriza essa visão alternativa. Quer dizer, ao buscar o resgate da legislação que abordou o tema das violências conjugais, fica claro também o importante instrumento de negociação e imposição que ela representou, especialmente para as mulheres. Não há meios de, simplesmente, ignorar essa trajetória e pretender desconstruir as conquistas políticas que culminaram com a Lei Maria da Penha. Afinal de contas, a necessidade de buscar tutela estatal, fugindo da repressão no âmbito doméstico, veio das próprias mulheres.

Enfim, se algo deve ser feito a partir dessas constatações, é a implementação e aplicação da Lei de modo a se refletir sobre seu papel, sem deixar de explorar proporcionalmente suas três dimensões, sobretudo a pedagógica e a protetiva. Não se pode privilegiar excessivamente a dimensão normativa, sob a pauta do Direito Penal, porque isso só fortaleceria os muros do Panóptico. A Lei Maria da Penha tem muito mais a dizer. Ao definir rigorosa e detalhadamente as violências psicológicas, quis dizer que a palavra das mulheres tem valor. Há direitos dos quais não se abre, simplesmente, mão. Isso não é possível porque há um passado que dá sentido a novas reivindicações e conquistas.

\section{REFERÊNCIAS}

ARENDT, Hannah. Responsabilidade e Julgamento. São Paulo: Companhia das Letras, 2004.

BARSTED, Leila Linhares; HERMANN, Jacqueline (Coord.). As Mulheres e os Direitos Humanos: os direitos das mulheres são direitos humanos. Rio de Janeiro: CEPIA, 2001. CEPIA, 1999.

Instrumentos Internacionais de Proteção aos Direitos Humanos. Rio de Janeiro:

BENÍTEZ ORTÚZAR, Ignácio F. La Violencia Psíquica a la luz de la Reforma del Código Penal en Materia de Violencia Doméstica. Disponível em: http://premium.vlex.com/doctrina/ Estudios-penales-violencia-domestica/Violencia-psiquica-luz-reforma-codigo-penal-materiaviolencia-domestica/2100-298577,01.html. Acesso em: 11 nov. 2008.

BRASIL, Projeto de Lei nº3/2003. Câmara dos Deputados. Disponível em: http://www2. camara.gov.br/proposicoes/loadFrame.html?link=http://www.camara.gov.br/internet/sileg/prop lista.asp?fMode=1\&btnPesquisar=OK\&Ano=2003\&Numero=3\&sigla=PL. Acesso em: 11 nov. 2008.

BRASIL. 2004 - ANO DA MULHER. Brasília: Ministério da Saúde, 2004.

CAMPOS, Carmen Hein de (Org.). Lei Maria da Penha: comentada em uma perspectiva jurídico-feminista. Rio de Janeiro: Lumen luris, 2011.

CARVALHO, Érika Mendes de. O Tratamento Penal da Violência Doméstica no Brasil: uma abordagem crítica. Revista da Associação Brasileira de Professores de Ciências Penais. São Paulo, ano 3, p. 207-233, jan./jul. 2006.

DIAS, Maria Berenice. A Lei Maria da Penha na Justiça: a efetividade da Lei 11.340/06 de combate à violência doméstica e familiar contra a mulher. São Paulo: Revista dos Tribunais, 2007. 
FOUCAULT, Michel. Vigiar e Punir: história da violência nas prisões. 37. ed., Rio de Janeiro: Vozes, 2009.

GOMES, Anderson Soares. Narrando Fatos: História e Historicidade em O Homem do Castelo Alto de Philip K. Dick. Disponível em: WWW.filologia.org.br/viiicnlf/anais/ caderno07-08.html. Acesso em 16 fev. 2009.

GREGORI, Maria Filomena. Cenas e Queixas: mulheres e relações violentas. Rio de Janeiro: Paz e Terra, 1993.

GROSSI, Miriam Pillar. Discours sur les femmes battues: représentations de la violence sur les femmes au Rio Grande do Sul. Université Paris V - René Descartes. Scinces Humaines. Paris : Sorbonne, 1988.

. Identidade de Gênero e Sexualidade. Antropologia em Primeira Mão. Florianópolis: PPGAS/UFSC, 1998.

GUERRA FILHO, Willis Santiago (Coord.). Dos Direitos Humanos aos Direitos Fundamentais. Porto Alegre: Livraria do Advogado, 1997.

HIRIGOYEN, Marie-France. A Violência no Casal: da coação psicológica à agressão física. Rio de Janeiro: Bertrand Brasil, 2006. Brasil, 2002.

Assédio Moral: a violência perversa no cotidiano. Rio de Janeiro: Bertrand

HUNT, Lynn. O Romance e as Origens dos Direitos Humanos: interseções entre História, Psicologia e Literatura. In: Varia Historia. Belo Horizonte, vol. 2, no 34, p. 267-289, jul. 2005.

KOSELLECK, Reinhart. O Futuro Passado dos Tempos Modernos. In: Futuro Passado. Contribuição à semântica dos tempos históricos. Rio de Janeiro: Editora PUC Rio, 2006.

LIBARDONI, Alice (Coord.). Direitos Humanos das Mulheres: em outras palavras. Subsídios para capacitação legal de mulheres e organizações. Brasília: AGENDE, 2002.

MENDES, Gilmar Ferreira; BRANCO, Paulo Gustavo Gonet. Curso de Direito Constitucional. 6. ed., rev. e atual. São Paulo: Saraiva, 2011.

MILLER, Mary Susan. Feridas Invisíveis: abuso não-físico contra mulheres. São Paulo: Summus, 1999.

MOLINA, Antonio García-Pablos de Molina; GOMES, Luiz Flávio. Criminologia. 4. ed., rev., atual e ampl. São Paulo: Revista dos Tribunais, 2002.

MONTMINY, Lyse. Older women's experiences of psychological violence in their marital relationships. Disponível em: http://www.haworthpress.com/web/JGSW, 2005.

PEDRO, Joana Maria; GROSSI, Miriam Pillar (Orgs.). Masculino, Feminino, Plural: gênero na interdisciplinariedade. Florianópolis: Ed. Mulheres, 1998.

PINHO, Leda de Oliveira. Princípio da Igualdade: investigação na perspectiva de gênero. Porto Alegre: Sérgio Antônio Fabris, 2005.

PIOVESAN, Flávia; IKAWA, Daniela (Coord.). Direitos Humanos - Fundamentos, Proteção e Implementação: perspectivas e desafios contemporâneos. Curitiba: Juruá, 2007.

RABINOW, Paul; DREYFUS, Hubert. Michel Foucault: uma trajetória filosófica - para além do estruturalismo e da hermenêutica. Rio de Janeiro: Forense Universitária, 1995. 
RIFIOTIS, Theóphilos. Derechos Humanos y Otros Derechos: aporias sobre procesos de judicialización e institucionalización de movimentos sociales. In: Alejandro Isla. (Org.). En los márgenes de la ley. Inseguridad y violencia en el cono sur. Buenos Aires, Barcelon, México: Paidós, 2007.

Nos Campos da Violência: diferença e positividade. In: Antropologia em Primeira Mão, v. 19, p. Florianópolis, 1997.

O Leitor-modelo no Caso da Polícia Militar na Favela Naval. In: Perspectiva, v. 13, no 4, São Paulo, 1999, p. 28-41.

ROVINSKI, Sonia Liane Reichert. Dano Psíquico em Mulheres Vítimas de Violência. Rio de Janeiro: Lumen Juris, 2004.

SABADELL, Ana Lúcia. Perspectivas Jussociológicas da Violência Doméstica: efetiva tutela de direitos fundamentais e/ou repressão penal. Revista dos Tribunais/ Fascículo Penal. São Paulo: Revista dos Tribunais, ano 94, v. 840.

SANTOS, Luciany Michelli Pereira dos. Assédio Moral nas Relações Privadas: uma proposta de sistematização sob a perspectiva dos direitos da personalidade e do bem jurídico integridade psíquica, 250 fls. Dissertação [Mestrado em Direito Civil]. Universidade Estadual de Maringá, Maringá, 2006.

SIQUEIRA JÚNIOR, Paulo Hamilton; OLIVEIRA, Miguel Augusto Machado de. Direitos Humanos e Cidadania. São Paulo: Revista dos Tribunais, 2007, p. 25-26.

SIRVINSKAS, Luis Paulo. Aspectos Polêmicos sobre a Lei $n^{\circ} 11.340$, de 7 de agosto de 2006, que cria mecanismos para coibir a violência doméstica e familiar contra a mulher, Revista Jurídica, ano 55, $\mathrm{n}^{\circ}$ 351, Porto Alegre: Nota Dez/Fonte do Direito, jan. 2007.

UNITED NATIONS. Convention on the Elimination of all forms of Discrimination Against Women: Considerations of reports submitted by States parties under article 18 of the Convention on the elimination of all forms of discrimination agains women Brazil. Disponível em: http://daccess-dds-ny.un.org/doc/UNDOC/GEN/N02/687/25/PDF/ N0268725.pdf?OpenElement. Acesso em: 19 set. 2012. 